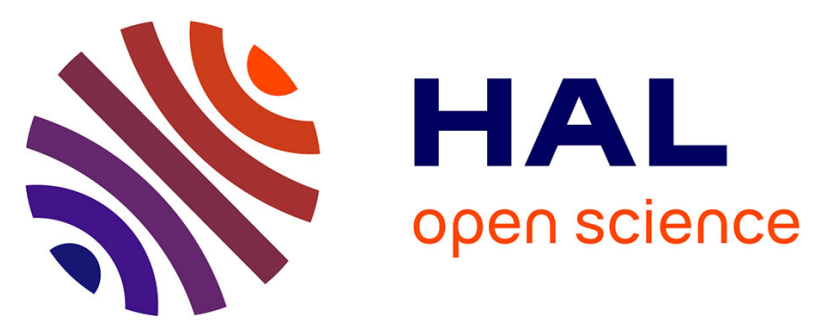

\title{
Estimation of Leaf Nitrogen Concentration of Winter Wheat Using UAV-Based RGB Imagery
}

\author{
Qinglin Niu, Haikuan Feng, Changchun Li, Guijun Yang, Yuanyuan Fu, \\ Zhenhai Li, Haojie Pei
}

\section{To cite this version:}

Qinglin Niu, Haikuan Feng, Changchun Li, Guijun Yang, Yuanyuan Fu, et al.. Estimation of Leaf Nitrogen Concentration of Winter Wheat Using UAV-Based RGB Imagery. 11th International Conference on Computer and Computing Technologies in Agriculture (CCTA), Aug 2017, Jilin, China. pp.139-153, 10.1007/978-3-030-06179-1_15 . hal-02111531

\section{HAL Id: hal-02111531 \\ https://hal.inria.fr/hal-02111531}

Submitted on 26 Apr 2019

HAL is a multi-disciplinary open access archive for the deposit and dissemination of scientific research documents, whether they are published or not. The documents may come from teaching and research institutions in France or abroad, or from public or private research centers.
L'archive ouverte pluridisciplinaire HAL, est destinée au dépôt et à la diffusion de documents scientifiques de niveau recherche, publiés ou non, émanant des établissements d'enseignement et de recherche français ou étrangers, des laboratoires publics ou privés. 


\title{
Estimation of leaf nitrogen concentration of winter wheat using UAV-based RGB imagery
}

\author{
Qinglin Niu ${ }^{12}$, Haikuan Feng ${ }^{23}$, Changchun $\mathrm{Li}^{1}$, Guijun Yang ${ }^{23(凶)}$, Yuanyuan $\mathrm{Fu}^{23}$, \\ Zhenhai $\mathrm{Li}^{23}$, Haojie Pei ${ }^{12}$ \\ ${ }^{1}$ School of Surveying and Land Information Engineering, Henan Polytechnic University, \\ Jiaozuo 454000, China \\ \{niuql2011, lichangchun610\}@126.com, xmljphj@163.com \\ ${ }^{2}$ Key Laboratory of Quantitative Remote sensing in Agriculture P.R.China, Beijing \\ Research Center for Information Technology in Agriculture, Beijing 100097, China \\ \{fenghaikuan123, fyy0201\}@163.com, yanggj@nercita.org.cn, \\ lizh323@126.com \\ ${ }^{3}$ National Engineering Research Center for Information Technology in Agriculture, Beijing
} 100097, China

\begin{abstract}
Leaf nitrogen concentration (LNC) of winter wheat can reflect its nitrogen (N) status. Rapid, non-destructive and accurate monitoring of LNC of winter wheat has important practical applications in monitoring $\mathrm{N}$ nutrition and fertilizing management. The experimental site of winter wheat was located at Xiaotangshan National Demonstration Base of Precision Agricultural Research located in Changping District, Beijing, China. High spatial resolution digital images of the winter wheat were acquired using a low-cost unmanned aerial vehicle (UAV) with digital camera system at three key growth stages of booting, flowering and filling during April to June in 2015. Firstly, the acquired UAV digital images were mosaicked to generate a Digital Orthophoto Map (DOM) of the entire experimental site and 15 digital image variables were constructed. Then, based on the ground measured data onto LNC and digital image variables derived from the DOM for 48 sampling plots of winter wheat, linear and stepwise regression models were constructed for estimating LNC. Finally, the optimum model for estimating LNC was screened out by comprehensively considering the coefficient of determination $\left(R^{2}\right)$, the root mean square error (RMSE), the normalized root mean square error ( $n R M S E)$ and the simplicity of model calibrating and validating. The experimental results showed that the linear regression model of $r / b$ that was one of the digital image variables for estimating LNC had the best accuracy with the model's calibration and validation of $R^{2}, R M S E$ and $n R M S E$ were $0.76,0.40,11.97 \%$ and $0.69,0.43$, $13.02 \%$, respectively. The results suggest that it is feasible to estimate LNC of winter wheat based on the DOM acquired by UAV remote sensing platform carrying a low-cost, high-resolution digital camera, which can rapidly and non-destructively obtains the LNC of winter wheat experiment site and provide a quick and low-cost method for monitoring $\mathrm{N}$ nutrition and fertilizing management.
\end{abstract}

Keywords: winter wheat, leaf nitrogen concentration (LNC), remote sensing, unmanned aerial vehicle (UAV), digital imagery, high-resolution

\section{Introduction}

Nitrogen (N) is one of the essential nutrient elements for crop growth and is closely related to the growth status, photosynthesis and yield of crops[1-2]. It is difficult to timely and appropriately computes the amount of fertilizer that crops need and to avoid excess fertilization according to the demand for crop growth. In addition, it has become an important issue to minimize the pollution of fertilizer to the environment while maintaining the high crop yield at the same time to achieve sustainable development 3. Leaf nitrogen concentration (LNC) is an important indicator of the crop $\mathrm{N}$ nutrition. It is an important guiding significance of crop $\mathrm{N}$ nutrition monitoring and fertilizer management to rapidly, non-destructively, accurately and low-costly estimate crop LNC using remote sensing technology [4-6].

Agriculture is one of the most important and widely used fields of remote sensing technology. Remote sensing technology has the characteristics of rapid, non-destructive and high-throughput acquisition of ground feature information and is developing towards the direction of quantification and high precision 7. Satellite, aviation, and proximal remote sensing are limited in the application of precision agriculture because of their limitations[4, 8-9]. Unmanned aerial vehicle (UAV) remote sensing has the advantages of easy platform construction, low operation and 
maintenance cost, flexible mobility, controllable flight height and short operation cycle[5,10-12].

Multispectral, hyperspectral or light detection and ranging (LIDAR) sensors are relatively heavy, which greatly reduces the flight time of UAV when mounted on, and these sensors are more expensive than digital cameras, and the subsequent processing of data is complex, which seriously hinders their extensive applications in precision agriculture [10, 13-16]. With the rapid development of UAV and sensor technology, UAV platforms and digital cameras are developed toward the mass consumption levels. They have the characteristics of low-price, miniaturization, light, and intelligence, and the spatial resolution of digital cameras is becoming higher and higher. The above reasons make it possible for a UAV to mounted with digital cameras as a low-cost remote sensing data acquisition platform, which has become a hot spot of practical research in precision agriculture [5, 10, 17-20].

At present, UAV remote sensing platform is equipped with low-cost and high-resolution digital cameras, which is used to estimate crop phenotypic parameters. The parameters are mainly about the morphological structure parameters. However, the crop physiological and biochemical parameters are few. In this study, high-resolution digital camera images were acquired and used to generate a DOM of the research area and corresponding LNC values of 48 sampling plots were measured synchronously. Linear and stepwise regression analysis models are constructed to estimate LNC of winter wheat using digital image variables from the DOM and measured LNC. In the end, the optimum model for estimating LNC was screened out by comprehensively considering the coefficient of determination $\left(R^{2}\right)$, root mean square error (RMSE), normalized root mean square error ( $n R M S E)$ and the simplicity of model calibrating and validating. This study proves that digital camera mounted on UAV remote sensing system can be applied to winter wheat to rapidly, non-destructively monitor and evaluate $\mathrm{N}$ nutrition and yield potential, which provides a rapid, low-cost and high efficient technical mean for $\mathrm{N}$ management and growth monitoring of winter wheat.

\section{Materials and methods}

\subsection{Experiment design}

The experiment was carried out from September 2014 to June 2015 at Xiaotangshan National Demonstration Base of Precision Agricultural Research $\left(40^{\circ} 10^{\prime} \mathrm{N}, 116^{\circ}\right.$ $26^{\prime}$ E) in Changping District, Beijing, China. It has a flat terrain with an altitude of $30 \mathrm{~m}$ above sea level and features a typical semi-humid continental monsoon climate. The soil type is fluvio-aquatic soil and the previous crop was maize. The winter wheat varieties were "zhongmai175 (ZM175)" and "jing 9843 (J9843)".

The size of winter wheat field was $85 \mathrm{~m} \times 32 \mathrm{~m}$. There were 48 sampling plots, 16 treatments, three replicates and orthogonal test. The area of each plot was $48 \mathrm{~m}^{2}$ (6 $\mathrm{m} \times 8 \mathrm{~m}$ ), and the planting spacing was $15 \mathrm{~cm}$. There were four different $\mathrm{N}$ level treatments, namely, 0kg urea/mu (N1), 13kg urea/mu (N2), 26kg urea/mu (N3) and $39 \mathrm{~kg}$ urea/mu (N4). Each of the 16 plots was treated with $\mathrm{N}$ at four different $\mathrm{N}$ levels (Fig.1). 


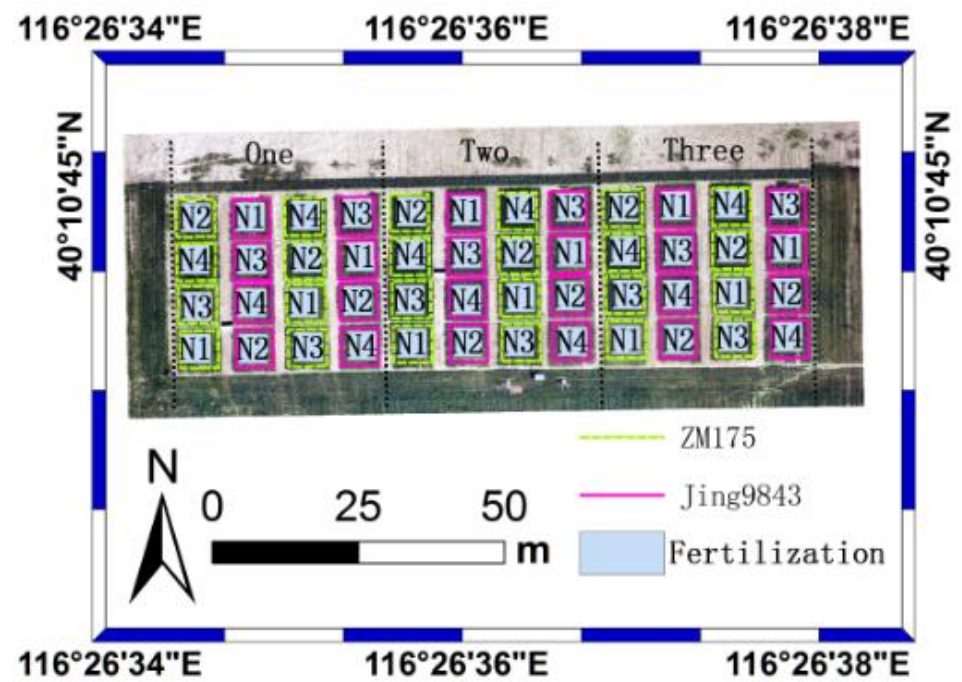

Fig. 1 Experiment design of variable rate fertilization of winter wheat

Note: N1, N2, N3, and N4 correspond to $0 \mathrm{~kg}$ urea $/ \mathrm{mu}, 13 \mathrm{~kg}$ urea $/ \mathrm{mu}, 26 \mathrm{~kg}$ urea $/ \mathrm{mu}$ and $39 \mathrm{~kg}$ urea/mu, respectively

\subsection{Acquisition and preprocessing of UAV digital images and LNC}

The winter wheat data of LNC and UAV high-resolution digital images were obtained at the booting stage (April 26, 2015), flowering stage (May 13, 2015) and filling stage (May 22, 2015). A fixed quadrat $(2 \times 0.15 \mathrm{~m} \times 1 \mathrm{~m})$ with group representation was selected as the sampling area for LNC measurements of every plot. In the fixed quadrat, the 20 winter wheat plants of representative were selected, and the leaves were placed in paper bags after organ separation. The picked leaves were then put into an oven with $105^{\circ} \mathrm{C}$ for a half-hour to inactivate enzymes in plants rapidly. Next, the oven will be set at $80^{\circ} \mathrm{C}$ for more than 48 hours until the weight remained unchanged. LNC (LNC, \%) was measured on crushed leaves using Kjeldahl apparatus (Buchi B-339, Sweden, FOSS). A total of 144 winter wheat samples were obtained at three key growth stages (The maximum value of LNC was $4.45 \%$, the minimum value of LNC was $1.16 \%$, the average value of LNC was $3.34 \%$, the standard deviation of LNC was 0.80 and the coefficient of variation of LNC was 0.24 ).

The UAV remote sensing data was obtained by data acquisition platform of an eight rotors electric UAV (single arm length:386mm, airframe net quality: $4.2 \mathrm{~kg}$, mass load: $6 \mathrm{~kg}$, endurance time: 15 20min) equipped with a high-resolution digital camera and position and orientation (POS) which aimed at acquiring the position and orientation information of digital camera. The high-resolution digital camera model was SONY Cyber-shot DSC-Q100 with the weight and size were $179 \mathrm{~g}$ and $62.5 \mathrm{~mm} \times 62.5$ $\mathrm{mm} \times 55.5 \mathrm{~mm}$; it had a 20 million pixel CMOS sensor and had a fixed focal length at $10 \mathrm{~mm}$ (fixed focus shooting). The high-resolution true color digital images of a spatial resolution of $0.013 \mathrm{~m}$ were obtained using the UAV system, which flew at the height of $50 \mathrm{~m}$ during 12:00-13:00 in synchronously with the ground data acquisition when the weather was clear and the solar radiation intensity was stable. The three UAV remote sensing experiments used the same design of flying routes.

The mosaic of UAV high-resolution digital images was performed with the aid of Agisoft PhotoScan software. The digital images were matched with the corresponding POS data and after photos alignment and dense cloud points building in PhotoScan. The optimized camera location parameters were estimated and sparse and dense cloud points of the experimental area were generated. A 3D polygon mesh model of experimental area was reconstructed based on the generated dense cloud points, which represented the surface geometry of winter wheat canopies. Finally, the canopy orthoimage of the winter wheat experimental area was generated and exported as TIFF format.

\subsection{Digital image variable selection}

The average digital number (DN) values of canopies red $(R)$, green $(G)$ and blue $(B)$ channels of each measured plot were extracted from canopy orthoimage of the winter wheat experimental area. The normalized red $(r)$, green $(g)$ and blue $(b)$ digital image 
variables were calculated based on the DN values from the canopy orthoimage. The normalized formulas were as follows[21-23]:

$$
\begin{aligned}
& r=\frac{R}{R+G+B} \\
& g=\frac{G}{R+G+B} \\
& b=\frac{B}{R+G+B}
\end{aligned}
$$

Where $R, G$, and $B$ were the DN values extracted from canopy orthoimage, respectively. According to the existing research results and the relationship between LNC and visible vegetation index, 12 vegetation indices within the range of visible light spectrum were selected. In this study, 15 digital image variables were selected to

\begin{tabular}{|c|c|c|c|}
\hline Image variable & Formula & Reference & Variable encoding \\
\hline$r$ & $r=r$ & $\checkmark$ & VI1 \\
\hline$g$ & $g=g$ & $\checkmark$ & VI2 \\
\hline$b$ & $b=b$ & $\checkmark$ & VI3 \\
\hline MGRVI & $\begin{array}{l}\text { MGRVI }=\left(g^{2}-r^{2}\right) / \\
\left(g^{2}+r^{2}\right)\end{array}$ & 19 & VI4 \\
\hline RGBVI & $\begin{array}{l}\text { RGBVI }=\left(g^{2}-b^{*} r\right) / \\
\left(g^{2}+b^{*} r\right)\end{array}$ & 19 & VI5 \\
\hline GRVI & GRVI $=(g-r) /(g+r)$ & 24 & VI6 \\
\hline GLA & $\begin{array}{c}\mathrm{GLA}=(2 * g-r-b) /( \\
2 * g+r+b)\end{array}$ & 25 & VI7 \\
\hline ExR & $\mathrm{ExR}=1.4 * r-g$ & 26 & VI8 \\
\hline ExG & $\mathrm{ExG}=2 * g-r-b$ & 27 & VI9 \\
\hline ExGR & $\begin{array}{c}\mathrm{ExGR}=\mathrm{ExG}-1.4 * \\
r-g\end{array}$ & 26 & VI10 \\
\hline CIVE & $\begin{array}{c}\text { CIVE }=0.441 * r-0 . \\
881 * g+0.385 * b+ \\
18.78745\end{array}$ & 28 & VI11 \\
\hline VARI & $\begin{array}{c}\mathrm{VARI}=(g-r) /(g+r- \\
b)\end{array}$ & 29 & VI12 \\
\hline$g / r$ & $g / r=g / r$ & $\checkmark$ & VI13 \\
\hline$g / b$ & $g / b=g / b$ & $\checkmark$ & VI14 \\
\hline$r / b$ & $r / b=r / b$ & $\checkmark$ & VI15 \\
\hline
\end{tabular}
estimate LNC of winter wheat (Table 1).

Table 1 Digital image variables associated with LNC

Note:" $\checkmark$ " indicates the experience of visible vegetation parameters and $r, g$, and $b$ represent normalized DN values of $R, G$ and $B$ channels from orthoimage.

\subsection{Methods and statistical analysis}

Firstly, the DN values of $R, G$ and $B$ channels were extracted based on the high-resolution digital orthoimage of winter wheat and the digital image variables were calculated. $70 \%$ of the total sample data were randomly selected as the modeling data set and the correlation between digital image variables and LNC was analyzed. Secondly, based on the result of above correlation analysis, the LNC estimation models were constructed by methods of the linear and stepwise regression analysis. The predictive ability of the LNC estimation models was evaluated by using remaining $30 \%$ sample data (as the validation dataset) that were not involved in model calibrating.

Linear regression analysis was based on the correlation analysis between digital image variables and LNC. The estimation model of LNC was constructed according to the absolute value of correlation coefficients from large to a small order for LNC. In stepwise regression analysis, the estimation model added or removed a variable at a time when the model was built.

At the same time, variables were reevaluated, including the degree of significance of the regression coefficients and whether to delete variables based on its importance. Predictor variables might be added or deleted several times until the best model was obtained. The Akaike information criterion (AIC) took into account the statistical fitting of the model and the number of variables fitted. A model with smaller AIC values needs to be selected firstly, which shows that the model obtains sufficient fit with fewer variables. 
The coefficient of determination $\left(R^{2}\right)$, the root mean square error $(R M S E)$ and the normalized root mean square error ( $n R M S E)$ were chosen as the indices to evaluate the accuracy of estimation and verification model. The larger $R^{2}$ of calibration and verification model and the smaller the corresponding RMSE and $n R M S E$, the better of the predictive ability of models. The computational formulas are as follows:

$$
\begin{aligned}
& R^{2}=\frac{\sum_{i=1}^{n}\left(X_{i}-\bar{X}\right)^{2}\left(Y_{i}-\bar{Y}\right)^{2}}{n \sum_{i=1}^{n}\left(X_{i}-\bar{X}\right)^{2} \sum_{i=1}^{n}\left(Y_{i}-\bar{Y}\right)^{2}} \\
& \text { RMSE }=\sqrt{\frac{\sum_{i=1}^{n}\left(Y_{i}-X_{i}\right)^{2}}{n}} \\
& \mathrm{n} R M S E=\frac{\text { RMSE }}{\bar{X}}
\end{aligned}
$$

In the formula, $\mathrm{X}_{i}, \overline{\mathrm{X}}, Y_{i}$ and $\bar{Y}$ represent the measured values, the mean value of measured value, the estimated value and the mean value of estimated value; $n$ represents the sample size of the model.

\section{Results and analysis}

\subsection{Correlation analysis between LNC of winter wheat and digital image variables}

$70 \%$ of the sample data, which contains a total of 101 items, were randomly selected as the modeling data set. The digital image variables were constructed based on the modeling data set and the correlation between digital image variables and LNC were calculated. The results of the correlation analysis were shown in Fig.2. The significance test of variables was carried out by referring to the table of critical values of correlation coefficients. When the degree of freedom of variable was 99 , the absolute value of the correlation coefficient was great than 0.26 , reaching 0.01 of the significant level. The degree of freedom of the correlation analysis was 99 in this study and the significance of the variable reached 0.01 significant level when the absolute value of the correlation coefficient of the variable was greater than 0.26 . The absolute value of the correlation coefficient between digital image variable, $r / b, b, r$, ExR, VARI, GRVI and $g / r$ and MGRVI, ExGR, $g / b$, CIVE, $g$ and GLA and ExG, RGBVI and LNC were 0.87, 0.84, 0.82, 0.75, 0.74, 0.73, 0.69, 0.61, 0.45, 0.41, 0.31, greater than 0.26 in Figure 2. The results of correlation analysis showed that the correlation between the selected digital image variables and LNC was 0.01 significant. 


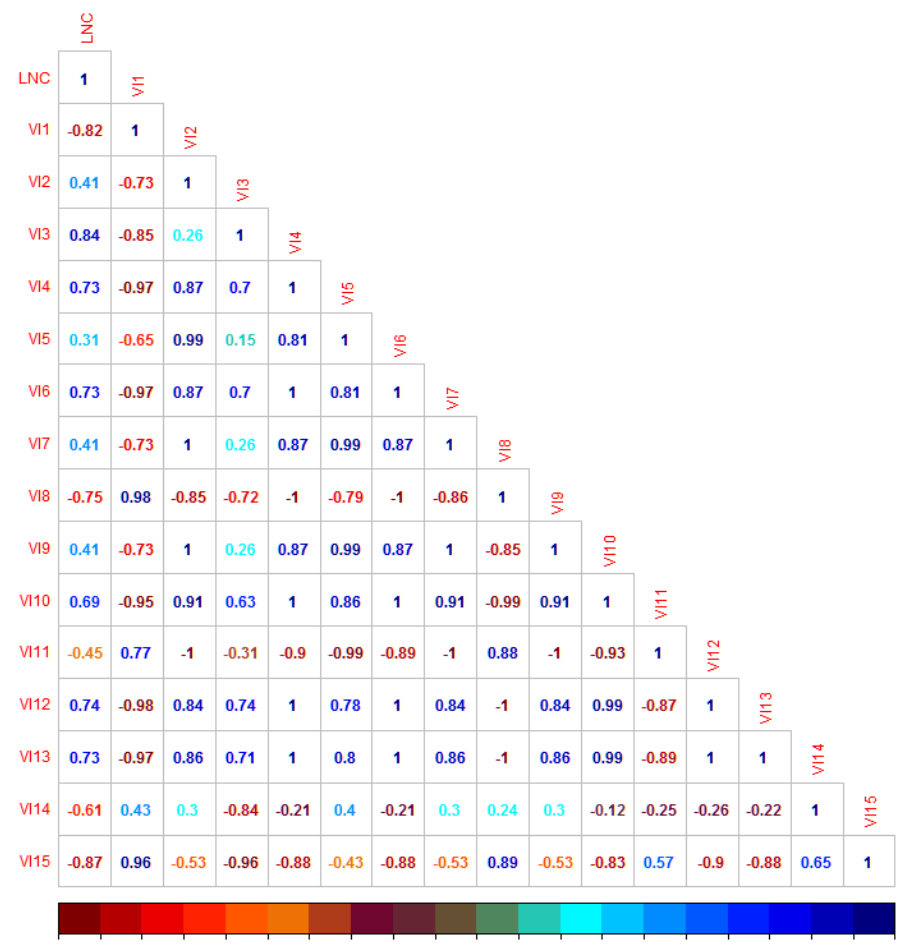

$\begin{array}{ccccccccccccccccccccc}-1 & -0.9 & -0.8 & -0.7 & -0.8 & -0.5 & -0.4 & -0.3 & -0.2 & -0.1 & 0 & 0.1 & 0.2 & 0.3 & 0.4 & 0.5 & 0.8 & 0.7 & 0.8 & 0.9 & 1\end{array}$

Fig.2 Result of Pearson correlation analysis between digital image variables and LNC

\subsection{Establishment of linear regression analysis model}

Based on the results of correlation analysis between digital image variables and LNC, the variables were sorted by correlativity. Then, a linear regression model of each digital image variable for estimating LNC was constructed. The results of linear regression analysis were shown in Table 2 . The AIC value, $R^{2}, R M S E$, and $n R M S E$ of the linear regression model were considered comprehensively. The optimal linear estimation model of LNC was chosen, whose variable was $r / b$. The AIC value, $R^{2}$, RMSE and $n R M S E$ of the optimal model were 108.66, 0.76, 0.40, 11.97\%, respectively.

Table 2 Result of linear regression analysis of digital image variables and LNC

\begin{tabular}{clllll}
\hline $\begin{array}{l}\text { Digital } \\
\text { image } \\
\text { variable }\end{array}$ & Regression equation & AIC value & $R^{2}$ & $R M S E$ & $n R M S E / \%$ \\
\hline$r / b$ & $\mathrm{y}=-5.06^{*} \mathrm{x}+9.67$ & 108.86 & 0.76 & 0.40 & 11.97 \\
$b$ & $\mathrm{y}=46.58^{*} \mathrm{x}-9.43$ & 126.66 & 0.71 & 0.44 & 13.07 \\
$r$ & $\mathrm{y}=-31.95^{*} \mathrm{x}+14.24$ & 140.14 & 0.67 & 0.47 & 13.97 \\
ExR & $\mathrm{y}=-15.81^{*} \mathrm{x}+4.82$ & 170.64 & 0.55 & 0.55 & 16.25 \\
VARI & $\mathrm{y}=8.58^{*} \mathrm{x}+2.49$ & 171.50 & 0.55 & 0.55 & 16.32 \\
GRVI & $\mathrm{y}=14.01^{*} \mathrm{x}+2.50$ & 176.39 & 0.53 & 0.56 & 16.72 \\
$g / r$ & $\mathrm{y}=6.34^{*} \mathrm{x}-3.83$ & 176.88 & 0.53 & 0.56 & 16.76 \\
MGRVI & $\mathrm{y}=7.08^{*} \mathrm{x}+2.50$ & 176.36 & 0.53 & 0.56 & 16.72 \\
ExGR & $\mathrm{y}=11.50^{*} \mathrm{x}+11.50$ & 188.35 & 0.47 & 0.60 & 17.74 \\
$g / b$ & $\mathrm{y}=-6.30^{*} \mathrm{x}+12.22$ & 205.56 & 0.37 & 0.65 & 19.32 \\
CIVE & $\mathrm{y}=-23.69^{*} \mathrm{x}+446.51$ & 229.98 & 0.20 & 0.73 & 21.80 \\
$g$ & $\mathrm{y}=29.02^{*} \mathrm{x}-7.80$ & 234.12 & 0.17 & 0.75 & 22.25 \\
GLA & $\mathrm{y}=13.89^{*} \mathrm{x}+1.82$ & 233.89 & 0.17 & 0.75 & 22.22 \\
ExG & $\mathrm{y}=9.67^{*} \mathrm{x}+1.87$ & 234.12 & 0.17 & 0.75 & 22.25 \\
RGBVI & $\mathrm{y}=5.91^{*} \mathrm{x}+2.03$ & 241.96 & 0.10 & 0.78 & 23.13 \\
\hline
\end{tabular}

\subsection{Establishment of stepwise regression analysis model}

The 15 digital image variables selected were analyzed by stepwise regression and the estimation models of LNC of winter wheat were constructed. The AIC value, $R^{2}$, $R M S E$, and $n R M S E$ of the stepwise regression model were calculated and the degree of significance of the coefficients of the regression model was judged. The results of stepwise regression analysis were shown in table 3. Evaluation indices of the stepwise regression analysis model were comprehensively considered. The optimal stepwise 
regression model for LNC of winter wheat was selected, consisting of 3 variables, $r$, $g / b$ and $r / b$. The regression equation of the optimal stepwise regression model was $\mathrm{LNC}=142.56 * r+12.18 * g / b-29.98 * r / b-24.91$, and the model's $R^{2}, R M S E$ and $n R M S E$ were $0.79,0.8,11.34 \%$, respectively.

Table 3 Result of stepwise regression analysis of digital image variables and LNC

\begin{tabular}{|c|c|c|c|c|c|}
\hline $\begin{array}{l}\text { Number of } \\
\text { independen } \\
\text { t variables }\end{array}$ & $\begin{array}{l}\text { AIC } \\
\text { value }\end{array}$ & $\begin{array}{l}\text { Significance of regression } \\
\text { coefficient }\end{array}$ & $R^{2}$ & RMSE & $\begin{array}{l}\mathrm{nRMSE} / \\
\%\end{array}$ \\
\hline 15 & 103.36 & $\begin{array}{l}\text { Neither of the } 16 \text { was } \\
\text { significant }\end{array}$ & 0.81 & 0.36 & 10.65 \\
\hline 6 & 96.65 & $\begin{array}{l}3 \text { were } 0.05 \text { significant, } 4 \text { were } \\
\text { not significant }\end{array}$ & 0.81 & 0.36 & 10.72 \\
\hline 5 & 97.47 & $\begin{array}{l}5 \text { were } 0.05 \text { significant, } 1 \text { was } \\
\text { not significant }\end{array}$ & 0.80 & 0.37 & 10.87 \\
\hline 4 & 100.16 & $\begin{array}{l}1 \text { was } 0.001 \text { significant, } 2 \text { were } \\
0.05 \text { significant, } 2 \text { were not } \\
\text { significant }\end{array}$ & 0.79 & 0.37 & 11.13 \\
\hline 3 & 100.15 & $\begin{array}{l}2 \text { were } 0.001 \text { significant, } 1 \text { was } \\
0.01 \text { significant, } 1 \text { was } 0.05 \\
\text { significant }\end{array}$ & 0.79 & 0.38 & 11.24 \\
\hline 2 & 108.11 & $\begin{array}{l}2 \text { were } 0.001 \text { significant, } 1 \text { was } \\
\text { not significant }\end{array}$ & 0.77 & 0.40 & 11.81 \\
\hline
\end{tabular}

Note: degree of significance, $, * * * ”: 0.001$, “**”:0.01, “*”:0.05.

\subsection{Optimal LNC estimation model selection}

The predictive ability of the linear and stepwise regression analysis model was evaluated using 101 sample data involved in modeling and 43 sample data not involved in modeling. The optimal estimation model was screened taking $R^{2}, R M S E$ and $n R M S E$ as evaluation indices and the results were shown in Table 4 and Figure 3.

Table 4 Comparison of LNC of winter wheat estimation models

\begin{tabular}{|c|c|c|c|}
\hline \multirow{2}{*}{$\begin{array}{l}\text { Regression } \\
\text { model }\end{array}$} & $\overline{R^{2}}$ & $R M S E$ & $n R M S E / \%$ \\
\hline & \multicolumn{3}{|c|}{ Modeling indicators (101 samples) } \\
\hline Linear & 0.76 & 0.40 & 11.97 \\
\hline \multirow[t]{2}{*}{ Stepwise } & 0.79 & 0.38 & 11.24 \\
\hline & \multicolumn{3}{|c|}{ Validating indicators (43 samples) } \\
\hline Linear & 0.69 & 0.43 & 13.02 \\
\hline Stepwise & 0.39 & 0.43 & 13.16 \\
\hline
\end{tabular}

The evaluation indices of model calibration and verification of LNC of winter wheat and the degree of simplicity of model application were considered comprehensively. The $R^{2}, R M S E$, and $n R M S E$ of linear regression model were compared with the stepwise regression model. The $R^{2}$ of linear regression was 0.76 , smaller than 0.03 from the stepwise regression model. The RMSE of linear regression model was 0.40 , 0.02 larger than that of the stepwise regression model. The $n R M S E$ of linear regression was $11.97 \%, 0.73 \%$ larger than that of the stepwise regression model. Therefore, the calibrating accuracies of linear and stepwise regression were approximate. However, model validation capabilities were evaluated using samples not involved in modeling. The $R^{2}, R M S E$, and $n R M S E$ of linear regression model validation were $0.69,0.43$ and $13.02 \%$, respectively. Compared with the stepwise regression model, $R^{2}$ and $R M S E$ were equal and $n R M S E$ was $0.14 \%$ smaller. The results showed that the linear regression model used only one variable and the stepwise regression model had three variables. The linear regression modeling variables were less than two and its predictive ability was a little better compared with the stepwise regression model. Comprehensively considering the accuracy and simplicity of the model, the linear regression model $\mathrm{LNC}=-5.06 * r / b+9.67$, which constructed by the digital image variable of $r / b$, was used to estimate LNC of winter wheat in this study. 


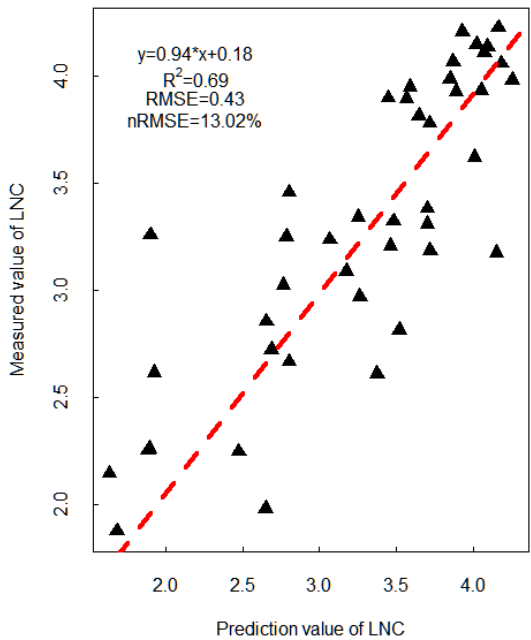

(a) Linear regression model

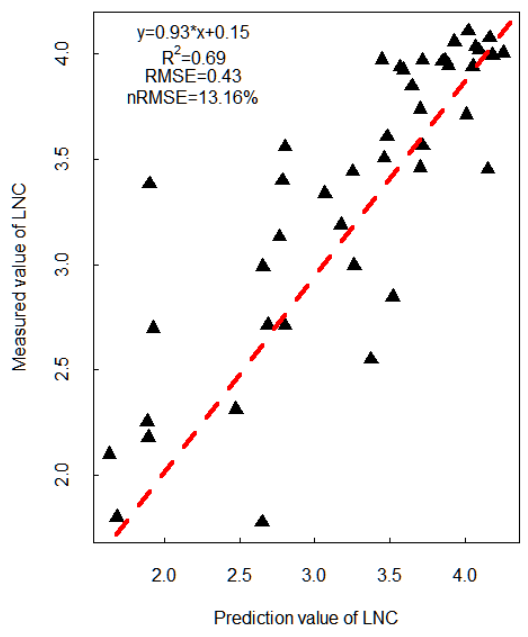

(b) Stepwise regression model

Fig. 3 Relationship of LNC of winter wheat between measured and model estimated values The spatial distribution of LNC of the winter wheat experimental area was estimated based on the optimal regression equation. The results of the LNC spatial distribution map were shown in Figure 4. The LNC in booting stage, flowering stage, and filling stage of winter wheat was significantly affected by $\mathrm{N}$ treatment. With the increase of $\mathrm{N}$ application rate, the corresponding LNC of winter wheat increased in turn. However, with the growth period advancing, LNC of winter wheat showed a downward trend and it was consistent with the physiological process of winter wheat $\mathrm{N}$ from the leaves to the grain. At booting stage of LNC, on the whole, LNC treated with N1 was between 2-3, LNC treated with N2 was between 3.5-4, LNC treated with $\mathrm{N} 3$ and N4 were more than 4 and LNC treated with N4 was much higher than that of $\mathrm{N} 3$. LNC in the flowering stage was lower than booting stage on the whole. However, LNC treated with $\mathrm{N} 1$ and $\mathrm{N} 2$ increased and still lower than that of N3 and N4. At the filling stage, LNC decreased as a whole, mainly due to the rapid transfer of $\mathrm{N}$ from leaves to grain.

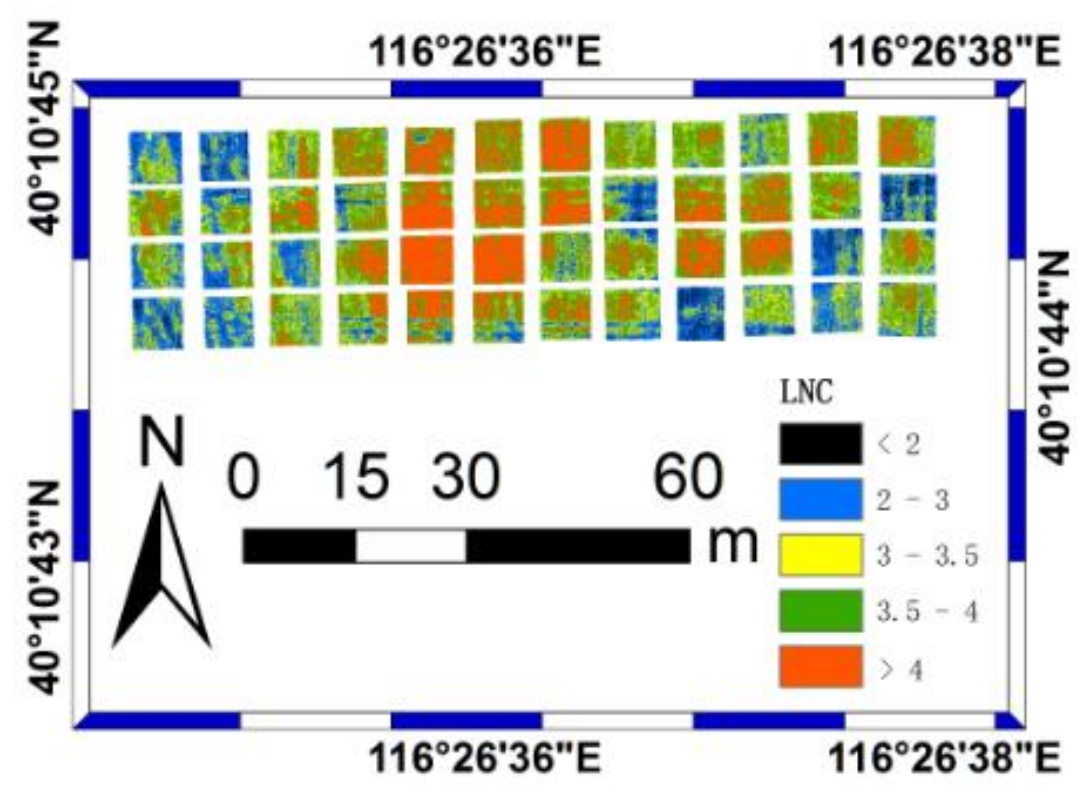

(a) Booting stage 


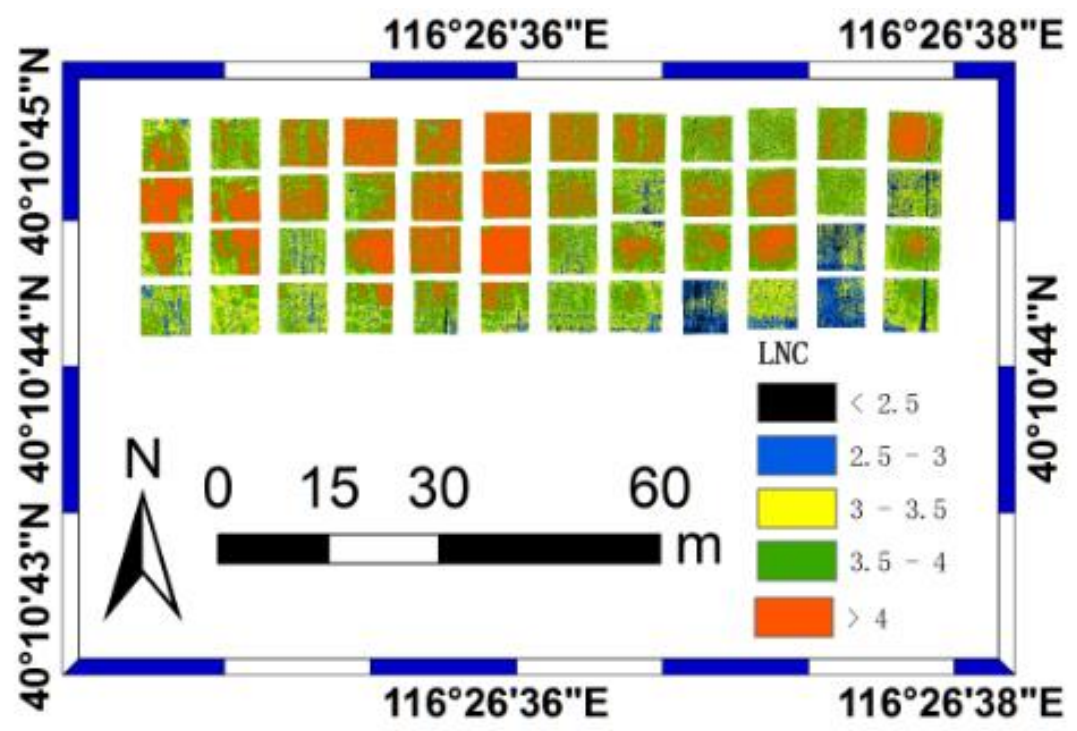

(b) Flowering stage

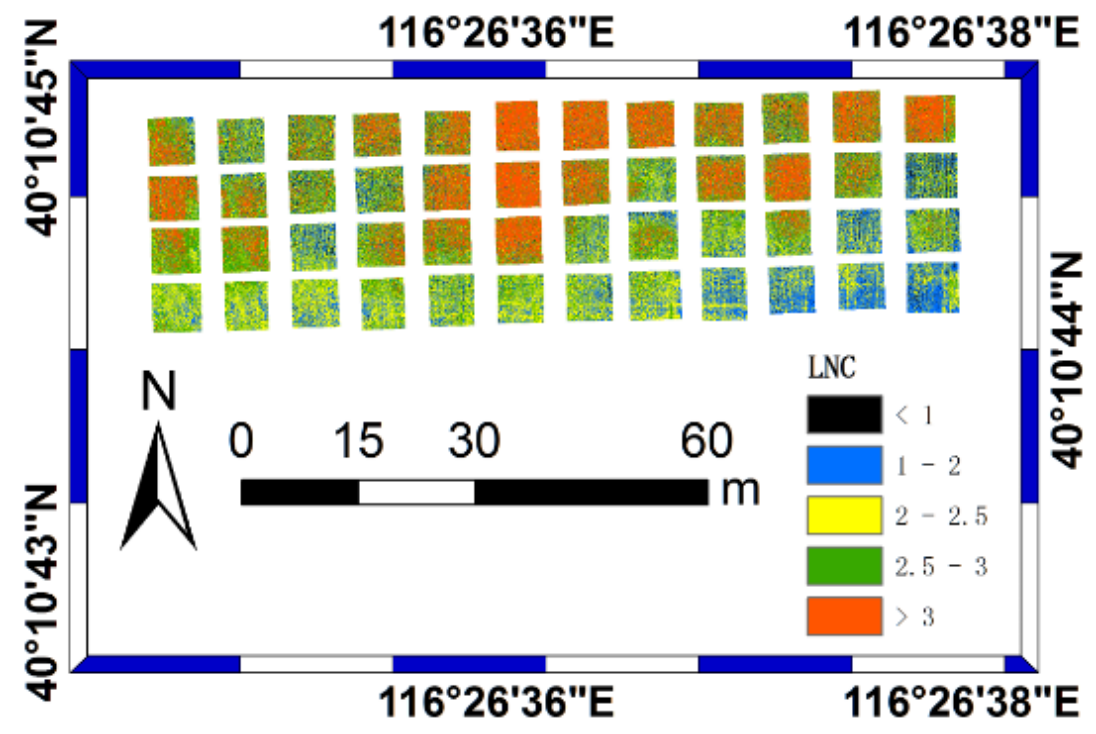

(c) Filling stage

Fig. 4 Spatial distribution of LNC estimation of winter wheat

\section{Discussion}

At present, rapid prediction of morphological structure and physiological and biochemical parameters of crops based on UAV remote sensing technology has become a hot spot of remote sensing research in precision agriculture. Yang 10 summed up the status of precision agricultural applications using UAV as the remote sensing platform, equipped with a variety of light remote sensing sensors. Jin 5 used UAV to carry low-cost and high-resolution digital camera flying at the height of 3 to 7 $\mathrm{m}$ and at the speed of $1 \mathrm{~m} / \mathrm{s}$ and obtained the high-resolution digital images of the experimental area. Then, the planting density of winter wheat was estimated with high precision. The above cases show that remote sensing platforms couple high-resolution digital cameras with UAVs have become one of the focuses of research because of their traits of low-cost, simple operation, convenient to use and high spatial resolution. However, relatively few studies on LNC of winter wheat are carried out based on UAV remote sensing platforms equipped with low-cost and high-resolution digital camera. In this study, the high-resolution digital orthoimages of UAV and measured LNC values were acquired at booting, flowering and filling stages of winter wheat. The linear regression model of $\mathrm{r} / \mathrm{b}$ was used to establish the estimation model of LNC based on the random selection of 101 sample data. By using the remaining 43 sample 
data which were not involved in modeling, the estimation model was validated. The analysis showed that the linear regression model of $r / b$ had higher accuracy when estimating LNC and the stability of the model was better, which is consistent with the results of [17-19, 23], using the digital images of UAV to estimate yield, LNC and biomass of maize, biomass of barley, leaf area index and yield of winter wheat. In the field of crop LNC estimation studies, the result of this study and the reference 17 using the visible vegetation indices based on orthoimage of UAV to estimate LNC of maize had the similar conclusion.

In this study, the LNC of winter wheat was estimated based on UAV high-resolution digital orthoimage. The linear regression estimation model of LNC constructed by digital image variable $\mathrm{r} / \mathrm{b}$, whether it can be well applied to LNC of winter wheat monitoring in other areas, needs further verification. As well as, whether similar problems such as the saturation effect of vegetation index will interfere with the predictive power of the LNC estimation model, which will serve as a follow-up research focus.

\section{Conclusion}

The high-resolution digital images were acquired for three winter wheat growth stages (booting, flowering, filling) using a UAV remote sensing platform with low-cost and high-resolution digital camera. Digital image variables were extracted based on the digital orthoimages. The correlation analyses of digital image variables and LNC were carried out and linear and stepwise regression models were constructed. The $R^{2}$, $R M S E$, and $n R M S E$ of model calibration and validation and the simplicity of model were evaluated comprehensively. Finally, the linear regression model constructed by $r / b$ was used to estimate the LNC of winter wheat. Conclusions were drawn as follows:

(1) The selected 15 digital image variables were significantly related to LNC at the 0.01 significance level. Among them, $r / b$ got the strongest correlation with LNC $(-0.87)$ and RGBVI got the weakest correlation with LNC (0.31).

(2) The LNC estimation models were established by selecting $70 \%$ of sample data at random (a total of 101 samples). The remaining 30\% sample data (a total of 43 samples) which were not involved in calibrating, were used to validate the estimation model. Among them, the $r / b$ linear regression estimation model was the best. The calibration and validation accuracy of this model $R^{2}=0.76, \quad R M S E=0.40$, $n R M S E=11.97 \%$ and $R^{2}=0.69, R M S E=0.43, n R M S E=13.02 \%$.

(3) UAV remote sensing platform equipped with low-cost and high-resolution digital camera can quickly, non-destructively and accurately estimate LNC of winter wheat from orthoimage, which provides a rapid and low-cost technique for $\mathrm{N}$ monitoring and $\mathrm{N}$ management in winter wheat.

\section{Reference}

1. Scheromm P, Martin G, Bergoin A, et al. Influence of nitrogen fertilization on the potential bread-baking quality of two wheat cultivars differing in their responses to increasing nitrogen supplies.[J]. Cereal Chemistry, 1993, 69:664-670.

2. Guo S L, Dang T H, Hao M D. Effects of Fertilization on Wheat Yield, NO_3 -N Accumulation and Soil Water Content in Semi-Arid Area of China[J]. Scientia Agricultura Sinica, 2005, 4(4):745-751.

3. Pjjr P, Hatfield J L, Schepers J S, et al. Remote sensing for crop management[J]. Photogrammetric Engineering \& Remote Sensing, 2003, 69(6):647-664.

4. Xu X G, Zhao C J, Wang J H, et al. Using optimal combination method and in situ hyperspectral measurements to estimate leaf nitrogen concentration in barley[J]. Precision Agriculture, 2014, 15(2):227-240.

5. Jin X, Liu S, Baret F, et al. Estimates of plant density of wheat crops at emergence from very low altitude UAV imagery[J]. Remote Sensing of Environment, 2017, 198.

6. Moharana S, Dutta S. Spatial variability of chlorophyll and nitrogen content of rice from hyperspectral imagery[J]. Isprs Journal of Photogrammetry \& Remote Sensing, 2016 122:17-29.

7. Zhao C J. Advances of research and application in remote sensing for agriculture [J]. Transactions of the Chinese Society for Agricultural Machinery, 2014, 45(12), 277-293.

8. Zhou W T, Wu B F, Zhang M, et al. Comprehensive monitoring of crop growth - take India as an example [J]. Journal of Remote Sensing, 2015,19(4):539-549. 
9. Tang J M, Liao Q H, Liu Y Q, et al. Estimating leaf area index of crops based on hyperspectral compact airborne spectrographic imager (CASI) data [J]. Spectroscopy and Spectral Analysis, 2015, 35(5):1351-1356.

10. Yang G, Liu J, Zhao C, et al. Unmanned aerial vehicle remote sensing for field-based crop Phenotyping: current status and perspectives[J]. Frontiers in Plant Science, 2017

11.Zhang C, Kovacs J M. The application of small unmanned aerial systems for precision agriculture: a review[J]. Precision Agriculture, 2012, 13(6):693-712.

12. Shun ping, SHAO, Xiao wei, et al. Framework of SAGI Agriculture Remote Sensing and Its Perspectives in Supporting National Food Security[J]. Journal of Integrative Agriculture, 2014, 13(7):1443-1450.

13. Candiago S, Remondino F, De Giglio M, et al. Evaluating Multispectral Images and Vegetation Indices for Precision Farming Applications from UAV Images[J]. Remote Sensing, 2015, 7(4):4026-4047.

14. Suomalainen J, Anders N, Iqbal S, et al. A Lightweight Hyperspectral Mapping System and Photogrammetric Processing Chain for Unmanned Aerial Vehicles[J]. Remote Sensing, 2014, 6(11):11013-11030.

15.Zhao X Q, Yang G J, Liu J G, et at. Estimation of soybean breeding yield based on optimization of spatial scale of UAV hyperspectral image [J]. Transactions of the CSAE, 2017,33(1): 110-116.

16. Nie S, Wang C, Dong P, et al. Estimating Leaf Area Index of Maize Using Airborne Discrete-Return LiDAR Data[J]. Remote Sensing Letters, 2016, 9(7):3259-3266.

17. Vergaradíaz O, Zamanallah M A, Masuka B, et al. A Novel Remote Sensing Approach for Prediction of Maize Yield Under Different Conditions of Nitrogen Fertilization[J]. Frontiers in Plant Science, 2016, 7.

18. Li W, Niu Z, Chen H, et al. Remote estimation of canopy height and aboveground biomass of maize using high-resolution stereo images from a low-cost unmanned aerial vehicle system[J]. Ecological Indicators, 2016, 67:637-648.

19. Bendig J, Yu K, Aasen H, et al. Combining UAV-based plant height from crop surface models, visible, and near-infrared vegetation indices for biomass monitoring in barley[J] International Journal of Applied Earth Observation \& Geoinformation, 2015, 39:79-87.

20. Schirrmann M, Giebel A, Gleiniger F, et al. Monitoring Agronomic Parameters of Winter Wheat Crops with Low-Cost UAV Imagery[J]. 2016, 8(9):706.

21. Saberioon M M, Amin M S M, Anuar A R, et al. Assessment of rice leaf chlorophyll content using visible bands at different growth stages at both the leaf and canopy scale[J]. International Journal of Applied Earth Observations \& Geoinformation, 2014, 32(10):35-45.

22. Torres-Sánchez J, López-Granados F, Peña J M. An automatic object-based method for optimal thresholding in UAV images: Application for vegetation detection in herbaceous crops[J]. Computers \& Electronics in Agriculture, 2015, 114(C):43-52.

23. Zhou X, Zheng H B, Xu X Q, et al. Predicting grain yield in rice using multi-temporal vegetation indices from UAV-based multispectral and digital imagery[J]. Isprs Journal of Photogrammetry \& Remote Sensing, 2017, 130:246-255.

24. Tucker C J. Red and photographic infrared linear combinations for monitoring vegetation[J]. Remote Sensing of Environment, 1979, 8(2):127-150.

25. Mounir Louhaichi, Michael M. Borman, Douglas E. Johnson. Spatially Located Platform and Aerial Photography for Documentation of Grazing Impacts on Wheat[J]. Geocarto International, 2001, 16(1):65-70.

26. Meyer G E, Neto J C. Verification of color vegetation indices for automated crop imaging applications[J]. Computers \& Electronics in Agriculture, 2008, 63(2):282-293.

27. Woebbecke D M, Meyer G E, Von Bargen K, et al. Color indices for weed identification under various soil, residue, and lighting conditions[J]. Transactions of the ASAE, 1995, 38(1): 259-269.

28. Kataoka T, Kaneko T, Okamoto H, et al. Crop growth estimation system using machine vision[C]//Advanced Intelligent Mechatronics, 2003. AIM 2003. Proceedings. 2003 IEEE/ASME International Conference on. IEEE, 2003, 2: b1079-b1083 vol. 2.

29. Gitelson A A, Viña A, Arkebauer T J, et al. Remote estimation of leaf area index and green leaf biomass in maize canopies[J]. Geophysical Research Letters, 2003, 30(5). 